\title{
Developing Pre-Laboratory Videos for Enhancing Student Preparedness
}

DOI:

10.1080/03043797.2019.1593322

\section{Document Version}

Accepted author manuscript

Link to publication record in Manchester Research Explorer

\section{Citation for published version (APA):}

Rodgers, T., Cheema, N., Vasanth, S., Jamshed, A., Alfutimie, A., \& Scully, P. (2019). Developing Pre-Laboratory Videos for Enhancing Student Preparedness. European Journal of Engineering Education.

https://doi.org/10.1080/03043797.2019.1593322

\section{Published in:}

European Journal of Engineering Education

\section{Citing this paper}

Please note that where the full-text provided on Manchester Research Explorer is the Author Accepted Manuscript or Proof version this may differ from the final Published version. If citing, it is advised that you check and use the publisher's definitive version.

\section{General rights}

Copyright and moral rights for the publications made accessible in the Research Explorer are retained by the authors and/or other copyright owners and it is a condition of accessing publications that users recognise and abide by the legal requirements associated with these rights.

\section{Takedown policy}

If you believe that this document breaches copyright please refer to the University of Manchester's Takedown Procedures [http://man.ac.uk/04Y6Bo] or contact uml.scholarlycommunications@manchester.ac.uk providing relevant details, so we can investigate your claim.

\section{OPEN ACCESS}




\section{Developing Pre-Laboratory Videos for Enhancing Student Preparedness}

T.L. Rodgers*, N. Cheema, S. Vasanth, A. Jamshed, A. Alfutimie, and P.J. Scully ${ }^{1}$

School of Chemical Engineering and Analytical Science, The University of Manchester, Manchester, UK

The Mill. School of Chemical Engineering and Analytical Science, The University of Manchester, Manchester, M13 9PL. tom.rodgers@manchester.ac.uk

${ }^{1}$ current address: School of Physics, National University of Ireland-Galway, Galway, Ireland 


\section{Developing Pre-Laboratory Videos for Enhancing Student Preparedness}

Laboratory practicals are used throughout science and engineering education as it allows students to undertake active learning and develop technical skills. It is therefore important that students arrive to these sessions as prepared as possible to maximise their learning potential. This paper analyses how student preparation affects how prepared they feel to undertake a laboratory practical. It also examines how pre-laboratory video material can affect this preparedness and student marks. Data on student preparedness and preparation is collected via surveys over three years of the same module. Data on video views and retention are collected from YouTube. Findings indicate that students' preparedness increases with time spent preparing, up to a plateau level where further preparation has little affect. Students who watch the pre-laboratory videos increase their preparedness and also increase their assessment mark. Guidelines for creating successful pre-activity videos have been developed and shown to be effective.

Keywords: rich-media, chemical engineering, student preparedness, practical work, practice based learning.

\section{Introduction}

Laboratory practicals are fundamental for any science or engineering related degree as they allow for key skills to be learnt outside of the lecture theatre. Laboratory experience allows the participant to take an active part in the learning procedure as the student is required to apply both procedural and conceptual knowledge (Hofstein 2004). This procedural and conceptual knowledge is stored in the long term memory and acts as a type of filter for understanding different aspects of the laboratory session (Germann, Haskins, and Auls 1996). It is therefore important that students are prepared for these sessions to maximise their learning. However, there has been a growing trend in academics who believe students are engaging less prior to and during preparation for classes. Frequently students are getting lost in complex experimental protocol and 
struggling in the laboratory as a result of inadequate preparation for practical sessions (Adams 2009). A nine-year study by Leeds Medical School showed a number of noticeable trends over this period (Whittle, Pell, and Murdoch-Eaton 2010). Due to an increase in accessible technology, from year to year the increase in reported practice of information technology (IT) skills has become evident. Unfortunately there was also an observable decrease in the reported practice and confidence within the laboratory (Whittle, Pell, and Murdoch-Eaton 2010). As a result of these worrying trends throughout incoming university students, there has been a recent emphasis on preparation for laboratory classes to ensure students maximise their learning.

Work was carried at the University of Leicester to examine ways of increasing student engagement through low-cost pre-lab material via Blackboard, a virtual-learning environment (Cann 2016). Although the quizzes had no contribution to their final grade, the quiz completion rate was high at the start of the study, 79\%. It was also seen that students were undertaking several attempts to try to better their quiz marks, which is most likely due to the students feeling the pressure to perform at the very early stages of their higher education careers. It should be made clear that this is not to be generalised for the entire duration of first year, but is potentially due to an increased amount of effort in the first few weeks of university only. Literature confirms that students' actual performance in their first year of university usually falls short of what they expect to do (Kuh 2004). The idea of early university anxiety resulting in an initial and somewhat short-lived increase in student work rate is reinforced by the completion rate falling to $40 \%$, which reflects the changing attitudes of students throughout the year as well as changing workloads. Staff involved in helping run the laboratory module noticed an increase in student preparedness as a result of engaging with the pre-lab material (though only anecdotally). 
A similar methodology was used at the University of British Columbia (Heinera, Banet, and Wieman 2014). On implementing pre-class assignments with associated assessed quizzes, they found the quiz completion rate to be $98.8 \%$. These results confirm the findings of Whittle and Bickerdike (2015) who investigated the effects of introducing online pre-lab material at the University of Leeds. The results showed that those who displayed a higher level of engagement with the pre-lab material (only missing one or fewer tasks) performed better in the module overall than those who were poorly engaged (missing three or more tasks), overall mark of $67.4 \%$ versus $55.2 \%$.

The University of Tennessee investigated students' perceptions on pre-class videos followed by an assessed quiz (Long, Logan, and Waugh 2016). Over $90 \%$ said the preclass video helped with their knowledge of the topic and over $80 \%$ said the video helped to prepare for this quiz; however, they suggested keeping the videos short and concise. Marcell (2008) conducted a similar study and found that providing regular online preclass quizzes resulted in an increase in reading-related questions in-class. This result is replicated by the work carried out by Deslauriers, Heiner, and Rieger (2012) and Urtel et al. (2006) who found that students asked twice as many questions in the semester which involved online quizzes compared to the semester which involved no online quizzes - showing increased interest in the subject. In 2009 the University of California introduced the idea of 'Learn Before Lecture' (LBL) into their teaching (Moravec et al. 2010), by providing some material in the form of pre-class videos or worksheets. In the year which LBL was introduced, the average exam performance increased by $21 \%$, showing the effectiveness of successfully implementing pre-class exercises on student performance.

ChemLabS was implemented in 2005 at The University of Bristol and involves a fully interactive Dynamic Laboratory Manual (DLM) (Harrison et al. 2011, Harrison et al. 
2015). The DLM contains videos and virtual instrumentation for pre-lab use followed by online assessments. Students had a positive response to this material. Encouraging students to engage with pre-lab material has eliminated time-wasting within the laboratory with students trying to follow experimental procedures without fully understanding what the experiment entails (Harrison et al. 2015).

It is clear that pre-laboratory material improves student learning and engagement, and that rich-media material in this area could be very useful. However, there are gaps in our understanding of how students use these materials and how this use affects their preparedness for laboratory sessions. Therefore, this study uses a combination of data to address the following questions:

- How do students interact with pre-laboratory videos?

- Is there a difference in use between study videos and general skills videos?

- Are pre-laboratory videos used after the sessions to help with assessments?

- Do pre-laboratory videos have an effect on student preparedness and learning?

- How does the amount of time of student preparation affect their preparedness?

The results presented here provide information on how students use pre-laboratory videos and is used to create a set of guidelines to help generate high quality video resources.

Although not focused on within this paper, it should also be mentioned that further improvements to student preparedness and learning could be achieved be examining the intended learning outcomes of the course and looking at the constructive alignment between these and the activities undertaken. 


\section{Background}

This study examines the effect of preparation and the use of the rich-media material provided in a first year undergraduate laboratory unit delivered at a large Russell Group UK university. The first year core chemical engineering laboratories are delivered across semester 1 and 2 to all first year students. For this study we have collected data on the course ran between October 2014 and April 2015, October 2015 and April 2016, and October 2016 and April 2017. The course contained a cohort of 279, 284, and 254 first year undergraduate students respectively, with the majority of the students aged between 18 and 20. Approximately $60 \%$ of the undergraduate students were British and approximately $70 \%$ identified as male.

The undergraduate students were familiar with the use of technology giving their familiarity and average score of 3.7/5.0 and with over 55\% of the class having looked at educational videos online before arriving at the university.

\section{Course Design}

For the first year laboratory unit each student undertakes 8 out of 12 experiments; 4 per semester. The experiments are divided into key topics, mass transfer, heat transfer, and transport. The topic of each experiment matches material taught within the other first year courses; however, it is not aligned in time, meaning that some experiments are undertaken before learning the theory in lectures, and some afterwards (Institution 2018) - see supporting information Table 1 for a full breakdown.

Each experiment is undertaken during a single lab session, and each lab session lasts 3 hours. Students undertake each experiment as a pair, and then the week after the laboratory session students have to submit an individual marked assessment piece for each experiment; each semester students have to produce two written 6 page lab reports, one A0 poster, and one 10 minute interview. With data analysis and writing these 
assessments are designed for about 7-8 hours of work. Feedback is given on the assessment in time for the next laboratory session. Each experiment is support by a demonstrator (often called Graduate Teaching Assistant), one demonstrator per 6 students. The demonstrators are there to help facilitate the students to help them if they have any problems, and to make sure that students are carrying out the experiments safely.

The preparation material for the laboratories consisted of three items:

1. Course handbook available as both online and paper copies, which provided a small amount of background theory to each experiment, the experiment methodology/operating instructions, and objectives of the experiment.

2. Extra material available on blackboard for each experiment providing additional information about the background and relevance to chemical engineering e.g. a digitized book chapter, or a journal paper.

3. Laboratory study videos. These videos provided a summary of the context, theory, experimental method, and learning outcomes of a particular experiment. These videos were produced as animations with videos of laboratory equipment with a length of 6-9 minutes each. These were not available during 2014-2015, 3 were available during 2015-2016 (1 in each set of 4 experiments), and 9 were available during 2016-2017 (3 in each set of 4 experiments).

As well as the laboratory study videos there were 2 general skills videos available for 2016-2017. These were not related to any experiment, but were applicable to the assessments for all experiments. These videos were on experimental errors, and plotting data. 


\section{Method}

\section{Data Collection}

To understand students' use of the videos, data from YouTube analytics was collected. This provided fine-grained data on the use of the videos including number of views, retention (number of people watching at a given time in the video expressed as a percentage of the number of people who start watching the video), demographics, and device used. The videos were unlisted so were only accessed through the links in Blackboard.

Surveys given to the students to access their use of the videos and their preparedness for the laboratory sessions were used across the 3 years, the surveys were issued at the end of the lab session on iPads which the students filled in anonymously before leaving; all surveys received were complete and had self-consistent responses. The survey in 20142015 was given to the students every other experiment $(2,4,6$, and 8$)$ which led to 829 responses (74\% completion rate); the survey in 2015-2016 was given to the students every other experiment $(2,4,6,8)$ which led to 814 responses ( $72 \%$ completion rate); and the survey in 2016-2017 was given to the students once at the end of experiment 4 which lead to 167 responses (66\% completion rate) - The surveys can be seen as Figure 4 in the supporting information.

In order to clarify and understand the survey results, two focus groups were carried out with the students, about an hour each, in 2017. The focus groups were carried out on a voluntary basis, with students attending after a first year lecture. Fifteen first year students took part in the focus groups ( 7 and 8) the makeup of which is believed to be representative of the first year cohort (based on end of year exam marks). A facilitator was used to guide the session and began with first explaining the reason for the focus 
group, then asking the open-ended questions below; which were developed from the survey results and YouTube data. The focus groups were recorded (audio only) so that the facilitator didn't have to worry about making notes during the sessions - all students gave their permission for the session to be recorded. The following question would only be asked once the conversation began to die down. The sequencing of questions followed a similar style to that of the survey;

1) What do you normally do to prepare for the lab?

2) How do you watch the pre-lab videos?

3) Students seem to rewind parts of the video and watch again. What is the reason for this?

4) In the survey only a small number of students felt $5 / 5$ prepared. What is stopping you feeling completely prepared?

Several demonstrators were also asked their thoughts on possible experimental improvements and to highlight any common mistakes made by students. Useful feedback from the demonstrators could be included for pre-lab materials; key questions were:

1) Throughout this experiment, what do students struggle with the most?

2) What do you have to teach the students before the experiment?

3) Any changes/improvements you would make to the experiment material?

\section{Statistical Analysis}

All the data collected in this paper is statistically tested, providing confidence in similarities and differences. For continuous data the normality of the distribution is checked using the Lilliefors test. The null hypothesis is that data come from a normally distributed population, where the null hypothesis does not specify which normal 
distribution; i.e., it does not specify the expected value and variance of the distribution; this means the critical values are lower than the one-sample Kolmogorov-Smirnov test, thus are more stringent. If the distributions are normal then the student $t$-test is used, if the distributions are not normal then a two-sample Kolmogorov-Smirnov test is also used with the $t$-test to provide added confidence.

For data from Likert scales normality is not checked as the $t$-test provides good statistical representation regardless of distribution and number of samples (Norman 2010, Sullivan and Artino 2013). All $t$-test results are presented as a probability of likeliness of coming from the same distribution, $p$, for readability.

\section{Results}

\section{Rich-Media Material Use}

The number of video views for the study videos was very consistent over the whole of the laboratory module; each week the average number of views per student was about 2. This was also consistent across the two years that the videos were available to the students, and was also consistent across the different videos. 
Table 1 shows the average number of weekly views per student broken down per semester to check if there is any difference in the student views. The distribution of the data is not normal (fails the null hypothesis for Lilliefors test with $p<0.0001$ ), and the data shows that there was no difference in use between any of the semesters, based on statistical testing. As the data is not normal it has been tested with a KolmogorovSmirnov test which produces a minimum value of $p=0.93$ for pairs tested. Repeating with a $t$-test provides $p$ values lower than the Kolmogorov-Smirnov test, but still show there is no difference between the samples - the value of $p$ would have to be less than 0.1 for them to be statistically different at a $10 \%$ confidence interval ${ }^{1}$. This is interesting as it means that even in semester 2 when the majority of the theory for the experiments has been covered in other courses, students are still watching the study videos. As there is no statistical difference between the video use in the different semesters, then a global average can be taken as 2.02 with a standard deviation of 0.28 .

The students were asked how many times they viewed the study videos both before and during/after the laboratory session (via a survey given in Semester 1 2016-2017), there was also an option for students to select that they had undertaken an experiment which did not have a video. This distribution can be seen in Figure 1; it is clear that there were more video views before the experiment than during/after. The average number of views before the experiment was 1.9 while the average during/after the experiment was $0.9^{2}$. This total number of views is higher than that seen using the YouTube data ; however, it is less than 1 view per student higher, this is most likely due to natural inflation, i.e. if one week a student has 1 view and another week has 2 views, they

\footnotetext{
${ }^{1}$ A two-factor ANOVA without replication produced $p=0.83$ for the 4 semester simultaneously, also agreeing with no difference between them.

${ }^{2}$ For the case of calculating these averages the option of 5 or more is taken as 5.
} 
would fill in 2 views on the survey as 1.5 views is not an option. Also, some of the students watch the videos together, which means that each students watches the video once, but the recorded YouTube value would be one. This means that two thirds of the views by the students are before the laboratory session, but over $50 \%$ of the students are also watching the study videos after the laboratory session to remind themselves of the information.

Figure 2 shows the link between the number of video views before the session and the number of views during/after the session. Although the views during/after the session were fewer than before the session it is clear that several of the students who opted not to watch the video before the session watched it later (due to the non-zero value for the students who selected zero views before the session).

This viewing behaviour is different to the behaviour seen for the general skills videos. In this case instead of a steady number of views, there is a drop off with only a minimal number of views by the fifth week (third experiment); this is due to the general skills videos being applicable to all the experiments and the students practicing the skills during the assessments. Thus students only re-watch the videos if they feel they need to enhance their skills.

As well as the number of views it is important to look at the retention of students watching the videos, as this is linked to how much of the video the students actually viewed. Figure 3 shows the variation of the retention with time through the videos. It can be seen that there is a different behaviour in the viewing patterns between the study videos and the general skills videos. For the study videos the retention is high throughout, with some areas of over $100 \%$ retention. This means that some of the students must have rewound the video to re-watch sections again, even though, on average, students were watching them twice. 
The high retention rate could be due to unintelligible content and therefore students having to rewind and re-watch as a result of this. Alternatively the high retention rate could be due to students deeming particular sections to be of importance and hence rewatching to ensure a good understanding. The feedback from students during the focus group with regards to the reason for rewinding was split between both options. The students believed the first minute of each section, and especially the first minute, to be "a key section" and therefore decided to re-watch to establish a full understanding. Students also commented that the background theory section in most of the videos was too densely packed with content and therefore resulting in "too much information in a small amount of time" meaning they had to rewind these parts.

The general skills videos have a much lower retention across the whole video with a drop in viewers right at the start. This is similar to viewing behaviour seen by Gillie et al. (2017) where they comment that the first few moments of the video can cause viewers to exit the video or skip forward. This is most likely as they are not linked to a particular activity. . The study videos have an average retention much higher than expected for a general video as found by Rodgers, Mabley, and Garforth (2017); this is highly likely due to the fact that they are very focused on the experiment the students must undertake. The general skills videos fall pretty much on the trend found by Rodgers, Mabley, and Garforth (2017), meaning that the retention is around the value expected for general educational videos based on the length of the video.

\section{Rich-Media Material Effectiveness}

It is very clear that the students use the rich-media material both before and during/after the laboratory session. The main uses of the videos are before the laboratory session; as 
was the aim, but does this use have an effect on their preparedness for the experiment they will undertake and on their learning during the experiment?

Students were surveyed during the laboratory sessions about how prepared they felt for the experiment they were undertaking. Figure 4 shows the distribution of this score, out of five, given by the students - with five being very prepared. Two base lines were available for this comparison; the first was the laboratory sessions in 2014-2015, Figure 4(a), as no video material was available during this year; the second was the experiments during 2015-2016 which had no videos, Figure 4(b). The scores given here have been compared in Table 2 and the average value and standard deviation are very similar; a t-test on the distributions shows that they are not statistically different. To see if the preparedness of the students increases if they have watched the videos, the distribution given from students who said they watched the videos, Figure 4(c), can be compared to both this base line and the distribution from the students who said they didn't watch the videos, Figure 4(d). Table 2 has the comparison of the average values and the similarity t-test, in both cases there is no statistical significance of the distributions being the same. Thus it can be inferred that watching the videos before the laboratory sessions makes the student feel more prepared for the sessions. It should also be noted that the standard deviation of the preparedness score for the students that did watch the video is lower, and looking at the distributions, no students who watched the video gave a score of 1 out of 5, and most of the 2's were also eliminated. This shows that the videos are a useful tool for the students who felt the least prepared ${ }^{3}$.

\footnotetext{
${ }^{3}$ It should be quickly noted that simply adding the distributions for "watched" and "not watched" produced a distribution that is statistically different with a higher average score than the "video not available" distribution.
} 
As the students felt more prepared for the experiments with videos it is important to see if this had any effect on their learning during the experiment. The only data available during this study that may provide information on this is the marks for the assessments the students undertook after each experiment. For the 2015-2016 year the ratio of the assessment marks for the experiments that had a video compared to those that didn't is 1.09 with a ratio of the standard deviations of $0.82(p<0.0001)$. This suggests that there is an increase in learning by the students when they have the video to watch and a reduction in the range of marks. It is also useful to compare the scaled marks achieved in 2015-2016 (mostly no videos available) to 2016-2017 (mostly videos available). To scale the marks, the average from the laboratory unit has been divided by the average mark for the other units in the first year, this removes any cohort bias effects, and the same process is carried out for the standard deviation. This produces:

2015-2016: 1.03 with a standard deviation ratio of 0.52 .

2016-2017: 1.06 with a standard deviation ratio of $0.52(p<0.0001)$.

Thus there is some improvement in the marks of the students when there are more videos available ${ }^{4}$

\section{Effect of Preparation}

The students were surveyed, in Semester 1 2016-2017, on the amount of time they prepare for an individual laboratory session before they arrived in order to see if this increased their preparedness for the experiment. The distribution of results is shown in Figure 5. More than a third of the students said they spend over 30 minutes preparing for the laboratory session beforehand, with only a small percentage of students spending

\footnotetext{
${ }^{4}$ The mark for the 2014-2015 cohort cannot be compared since for 2015-2016 the learning objectives and assessment mark sheets were completely redesigned.
} 
no time or less than five minutes preparing for each session. The number of students spending more than 30 minutes preparing for a laboratory session seems low; however, this is how the students anonymously recorded their preparation time. This could be due to students relying on time at the start of the laboratory sessions to prepare, and should be examined further.

The preparation time can be compared to the number of video views to see if people that spent longer preparing are simply watching the videos more times, or if they are undertaking other preparation as well. The average number of views of the videos per student increases as the student preparation time increases. Taking the average video length to be about 7 minutes, then it can be shown that as the preparation time increases the amount of time the students are preparing by not watching the videos increases, with an increasing percent of the time not spent watching the videos.

The distributions of student preparedness were classified according to the selected preparation time, Table 3 . The average level of preparedness prior to the practical session increases with the amount of time spent using the pre-laboratory resources. A ttest analysis of the pairs was run, and it was found that the only two results that were significantly different from each other were at the 5 to 10 minutes, and the 10 to 20 minutes. This shows that through this region of preparation there is a change in the level of preparedness of the students. Figure 6 shows the average level of preparedness plotted against the amount of time spent preparing for the laboratory. Students who did not spend any time preparing for the laboratory session beforehand felt more prepared than students who spend less than about 7 minutes preparing for the material; this region can be thought of as a "Realisation Drop". This result can be explained by comments provided by students at the focus groups that there is a large amount of information needed for the experiments some of which is complicated. This could have 
resulted in the students feeling less prepared for the laboratory session due to them now being aware of what they did not understand in the material, as compared to students who never viewed the pre-laboratory material.

During the middle region, i.e. from about 5 to 25 minutes, there is an "Active Gain" in the preparedness of the students, this shows that they are spending time understanding what they need to do; watching the videos and reading the laboratory handbook. After about 25 minutes there is very little gain in the preparedness level of the students as they reach a "Confidence Plateau", i.e. their preparedness level is limited by their own confidence and the quality of the material. This implies that a much larger time spent on the pre-laboratory material may not be entirely effective.

This profile is similar to that seen due to the Dunning-Kruger effect (Kruger and Dunning 1999), but with preparation time rather than ability. It links to the fact that students who have not prepared overestimate their ability.

It should be noted here that although preparation time is an important factor for student preparedness, and there is obviously a link between the two, the time spent preparing isn't the only important part of preparation. The preparation activity undertaken is also important to the preparation and although the videos provide information for the students, active student learning could include the preparedness of the students, e.g. taking notes in a lab book. The students who spend longer preparing have more time on average to undertake other activities over just watching the videos.

\section{Guidelines for pre-laboratory videos}

The data collected for this paper and information collected from focus groups with students and the teaching assistants for the laboratory allows the generation of some guidelines for the production of pre-laboratory videos to achieve maximum effect, Table 4. 
Using the guidelines in Table 4, a new video was created and given to a test group of students to access its quality - an outline of the content can be seen as table 2 in the supporting information (Authors 2017). Table 5 shows the results of a survey given to the test group about the new video and its comparison with the same questions asked previously about the original videos.

\section{Conclusions}

A model has been created for student preparedness, showing how their preparedness changes with the amount of preparation they have carried out. There are three regions; the "Realisation Drop", where the preparedness drops over short times; the "Active Gain", where the preparedness increase over time; and the "Confidence Plateau", where more time spent preparing has very little effect on the preparedness level. This model can be used to benchmark strategies of pre-activity materials to allow comparison of their usefulness for students. Material developed for pre-laboratory use needs to have a strong link between it and the learning objectives of the experiments. Good prelaboratory materials would have a small realisation drop, so that it is accessible to students and not too information dense at the start to put students off; a steep active gain region, so that the students can learn the key material in a short period of time; and a high confidence plateau, so that the students are a prepared as possible.

This study has shown that videos used for pre-laboratory preparation are successful, increasing not only the preparedness of the students but also the marks gained in their assessment. Guidelines for the creation of pre-laboratory videos have been provided and tested showing an improvement in the video quality and usefulness. Activities such as marked pre-laboratory quizzes and marking lab-books should help to increase student preparedness for sessions. Further studies should focus on the type and quality of the 
preparation undertaken by students, and link this to the marks gained by the students.

\section{References}

Adams, D. 2009. "Current Trends in Laboratory Class Teaching in University Bioscience Programmes." Bioscience Education no. 13 (1):1-14. doi: 10.3108/beej.13.3.

Authors. 2017. Pressure Loss in Pipe Fittings. YouTube, https://www.youtube.com/watch?v=-R-C05igmdI.

Cann, A. 2016. "Increasing Student Engagement with Practical Classes Through Online Pre-Lab Quizzes." Journal of Biological Education no. 50 (1):101-112. doi: 10.1080/00219266.2014.986182.

Deslauriers, L. , C. Heiner, and G. Rieger. Pre-Reading Assignments - Why they may be the most important homework for your students. The University of British Columbia 2012 [cited 05/06/2017.

Germann, Paul J., Sandra Haskins, and Stephanie Auls. 1996. "Analysis of nine high school biology laboratory manuals: Promoting scientific inquiry." Journal of Research in Science Teaching no. 33 (5):475-499. doi: 10.1002/(SICI)10982736(199605)33:5<475::AID-TEA2>3.0.CO;2-O.

Gillie, M., R. Dahli, F. C. Saunders, and A. Gibson. 2017. "Use of rich-media resources by engineering undergraduates." European Journal of Engineering Education no. 42 (6):1496-1511. doi: 10.1080/03043797.2017.1306488.

Harrison, T., K. Hanford, B. Cheesman, G. Kaur, S. Franklin, A. Laurain, M. Medley, A. Rivett, K. Shallcross, K. Shaw, S. Williams, D. Shallcross, and L. Sellou. 2011. "The many positive impacts of participating in outreach activities on postgraduate students." New Directions no. 7:13-17.

Harrison, T., J. Slaughter, D. Shallcross, and N. C. Norman. 2015. A dynamic laboratory manual : Pre-lab online support for practical Chemistry. . In Innovative pedagogies series. UK: Higher Education Academy UK Physical Sciences Centre.

Heinera, C. E., A. I. Banet, and C. Wieman. 2014. "Preparing students for class: How to get $80 \%$ of students reading the textbook before class." American Journal of Physics no. 82:989-996.

Hofstein, Avi. 2004. "The Laboratory in Chemistry Education: Thirty Years of Eexperience with Developments, Implementation, and Research." Chemistry Education Research and Practice no. 5 (3):247-264. doi: 10.1039/B4RP90027H.

Institution, Authors. MEng Chemical Engineering 2018 [cited 23/08/2018. Available from

http://www.manchester.ac.uk/study/undergraduate/courses/2018/03848/mengchemical-engineering/course-details/\#course-profile.

Kruger, Justin, and David Dunning. 1999. "Unskilled and Unaware of It: How Difficulties in Recognizing One's Own Incompetence Lead to Inflated SelfAssessments." Journal of Personality and Social Psychology no. 77:1121-1134.

Kuh, G. 2004. "Student engagement in the first year of college." In Challenging and Supporting the First-Year Student : A Handbook for Improving the First Year of College, edited by M. L. Upcraft, J. N. Gardner and B. O. Barefoot, 86-107. Wiley. 
Long, Taotao, Joanne Logan, and Michael Waugh. 2016. "Students' Perceptions of the Value of Using Videos as a Pre-class Learning Experience in the Flipped Classroom." TechTrends no. 60 (3):245-252. doi: 10.1007/s11528-016-0045-4.

Marcell, Michael. 2008. "Effectiveness of Regular Online Quizzing in Increasing Class Participation and Preparation." International Journal for the Scholarship of Teaching and Learning no. 2 (1):Article 7.

Moravec, Marin, Adrienne Williams, Nancy Aguilar-Roca, and Diane K. O'Dowd. 2010. "Learn before Lecture: A Strategy That Improves Learning Outcomes in a Large Introductory Biology Class." CBE-Life Sciences Education no. 9 (4):473481. doi: 10.1187/cbe.10-04-0063.

Norman, Geoff. 2010. "Likert scales, levels of measurement and the "laws" of statistics." Advances in Health Sciences Education no. 15 (5):625-632. doi: 10.1007/s10459-010-9222-y.

Rodgers, T. L., S. Mabley, and A. A. Garforth. 2017. "Understanding Student Use of Resources in "Rich-Media" Courses." Journal of Chemical Engineering Education no. 20:22-31.

Sullivan, Gail M., and Anthony R. Artino. 2013. "Analyzing and Interpreting Data From Likert-Type Scales." Journal of Graduate Medical Education no. 5 (4):541-542. doi: 10.4300/JGME-5-4-18.

Urtel, M., R. Bahamonde, A. Mikesky, and J. Vessely. 2006. "On-line quizzing and its effect on student engagement and academic performance." Journal of Scholarship of Teaching and Learning no. 6 (2):84-92.

Whittle, S., and S. Bickerdike. 2015. "Online Preparation Resources Help First Year Students to Benefit from Practical Classes." Journal of Biological Education no. 49 (2):139-149. doi: 10.1080/00219266.2014.914554.

Whittle, S., G. Pell, and D. Murdoch-Eaton. 2010. "Recent changes to students' perceptions of their key skills on entry to higher education." Journal of Further and Higher Education no. 34 (4):557-570. doi: 10.1080/0309877X.2010.512082. 
Table 1. Average weekly views of each video per student separated by semester, including the standard deviation. The probabilities are created from the $t$-test as this produces the lowest $p$ values (so most conservative).

\begin{tabular}{|c|c|c|c|c|}
\hline & \multicolumn{2}{|c|}{ Semester 1} & \multicolumn{2}{|c|}{ Semester 2} \\
\hline \multirow{2}{*}{ 2015-2016 } & \multirow{4}{*}{$\begin{array}{l}\widetilde{\sigma} \\
0 \\
11 \\
2\end{array}$} & $2.08 \pm 0.24$ & $2.02 \pm 0.30$ & \multirow[b]{2}{*}{$\begin{array}{l}\infty \\
0 \\
0\end{array}$} \\
\hline & & \multicolumn{2}{|c|}{$p=0.64$} & \\
\hline \multirow{2}{*}{ 2016-2017 } & & $2.01 \pm 0.34$ & $1.96 \pm 0.26$ & II \\
\hline & & \multicolumn{2}{|c|}{$p=0.74$} & \\
\hline
\end{tabular}


Table 2. Average preparedness scores, the standard deviations, and the t-test probabilities of similarity of the mean of the distributions.

\begin{tabular}{|c|c|c|c|c|}
\cline { 2 - 5 } \multicolumn{1}{c|}{} & \multirow{2}{*}{\multicolumn{2}{c|}{$2014-15$}} & \multicolumn{3}{c|}{$2015-16$} \\
\cline { 3 - 5 } \multicolumn{1}{c|}{} & & No Video & Watched & Not Watched \\
\hline Average & 3.31 & 3.37 & 3.83 & 3.06 \\
\hline StDev & 1.08 & 0.95 & 0.76 & 1.07 \\
\hline$p$ & \multicolumn{3}{|c|}{0.26} & \multicolumn{2}{c|}{0.0001} \\
\hline$p$ & & \multicolumn{2}{|c|}{$<0.0001$} & \\
\hline
\end{tabular}


Table 3. Average preparedness scores, the standard deviations, and the t-test probabilities of similarity of the distributions for students with different preparation time.

\begin{tabular}{|c|c|c|c|c|c|c|}
\cline { 2 - 8 } \multicolumn{1}{c|}{} & \multicolumn{7}{c|}{ Preparation time / min } \\
\cline { 2 - 8 } \multicolumn{1}{c|}{} & 0 & $<5$ & $5-10$ & $10-20$ & $20-30$ & $>30$ \\
\hline Average & 2.33 & 1.67 & 2.24 & 2.96 & 3.28 & 3.40 \\
\hline StDev & 0.58 & 0.71 & 0.97 & 0.98 & 0.69 & 0.76 \\
\hline$p$ & \multicolumn{2}{|c|}{0.18} & \multicolumn{2}{c|}{0.03} & \multicolumn{2}{c|}{0.39} \\
\hline$p$ & & \multicolumn{2}{c|}{0.09} & \multicolumn{2}{c|}{0.17} & \\
\hline
\end{tabular}


Table 4. A set of guidelines to consider when producing future pre-lab videos and reasoning behind the chosen guidelines.

\begin{tabular}{|c|c|}
\hline Guideline & Reason \\
\hline $\begin{array}{l}\text { (1) Split the video into clear sections: e.g. } \\
\text { learning objectives, background theory, } \\
\text { useful equations, relevance etc. }\end{array}$ & $\begin{array}{l}\text { Makes the video easy to follow and } \\
\text { students can quickly find necessary } \\
\text { sections. } \\
\text { - Survey feedback shows videos are not } \\
\text { watched as much after laboratory sessions } \\
\text { therefore the video must include content } \\
\text { that can be utilised outside of labs. }\end{array}$ \\
\hline $\begin{array}{l}\text { (2) Include a sufficient amount of background } \\
\text { theory early on in the video: Assume that } \\
\text { most students are watching the video with } \\
\text { no prior knowledge on the topic. }\end{array}$ & $\begin{array}{l}\text { - Sets the scene for the rest of the video, } \\
\text { students think of the first minute as the } \\
\text { most important. } \\
\text { - Those experiments that are carried out } \\
\text { early on in the year are usually completely } \\
\text { unfamiliar to students. } \\
\text { - "It is important for students to have some } \\
\text { idea of the theory before entering the } \\
\text { laboratory. Completing a practical without } \\
\text { understanding the fundamental concepts is } \\
\text { meaningless"--Lab-demonstrator. }\end{array}$ \\
\hline $\begin{array}{l}\text { (3) Show images of the apparatus when } \\
\text { describing the experimental procedure. }\end{array}$ & $\begin{array}{l}\text { - "Experimental instructions without } \\
\text { images of the apparatus is like trying to } \\
\text { learn a computer game without seeing } \\
\text { the game controller" - Student. }\end{array}$ \\
\hline $\begin{array}{l}\text { (4) Keep the video concise and straight to } \\
\text { the point: Do not pack the video with too } \\
\text { much content, and only include necessary } \\
\text { information. Keep the terminology clear, } \\
\text { and explain key concepts. }\end{array}$ & $\begin{array}{l}\text { - "Current videos contain too much } \\
\text { information in a small amount of time" - } \\
\text { Student. } \\
\text { - "If a lot of unfamiliar words are used it } \\
\text { makes the video difficult to follow and } \\
\text { not user-friendly" - Student. } \\
\text { - Too much content results in students } \\
\text { having to re-wind and re-watch. } \\
\text { - Videos should be concise and clear } \\
\text { (Long, Logan, and Waugh 2016) }\end{array}$ \\
\hline $\begin{array}{l}\text { (5) Ensure the video narrator speaks clearly } \\
\text { but not too quickly - normal } \\
\text { conversation pace. }\end{array}$ & $\begin{array}{l}\text { - "As an international student, I find the } \\
\text { current videos easy to follow as the } \\
\text { narrator speaks very clearly"- Student } \\
\text { - Information should be delivered at an } \\
\text { appropriate pace (Long, Logan, and } \\
\text { Waugh 2016). }\end{array}$ \\
\hline
\end{tabular}


(6) Include a "Feedback from Demonstrator" or "Things to Remember" section. This section makes the students aware of the common, time-consuming mistakes made within the laboratory.
- "It is beneficial for students to make mistakes, but certain mistakes can be very time consuming in an already timelimited session" - Lab-demonstrator. 
Table 5. Scores for the new and old videos.

\begin{tabular}{|c|c|c|}
\hline Question & $\begin{array}{c}\text { Old Videos } \\
\text { Average Score }\end{array}$ & New Video \\
\hline $\begin{array}{c}\text { How useful is this video as pre-lab } \\
\text { material? }\end{array}$ & 4.20 & 4.80 \\
\hline $\begin{array}{c}\text { How much did this video help with } \\
\text { your knowledge of this particular } \\
\text { topic? }\end{array}$ & 4.04 & 4.50 \\
\hline How easy is the video to follow? & $/$ & 4.50 \\
\hline $\begin{array}{c}\text { How would you rate the overall } \\
\text { quality of the video? }\end{array}$ & $/$ & 4.80 \\
\hline
\end{tabular}


Figure 1. Variation of the number of video views (a) before the laboratory session and (b) during/after the laboratory session.

Figure 2. Average number of views during or after the laboratory session versus the number of before session views (5 represents 5 or more views).

Figure 3. Retention versus time through video for (a) three example study videos and (b) the two general skills videos.

Figure 4. Histograms of the preparedness score given by the students. 5 is very prepared, 1 is not prepared. (a) 2014-2015 score with no videos (829 responses), (b) 2015-2016 experiments with no videos available (518 responses), (c) 2015-2016 watched the video (242 responses), (d) 2015-2016 did not watch the video (54 responses).

Figure 5. Variation of the preparation time for laboratory session from 167 responses.

Figure 6. Variation of the average preparedness score with time spend preparing for the laboratory session, data taken from Table 3, with the time for each range taken as the arithmetic mean of the range. The black line is to guide the eye and is not a data fit. 
(a)

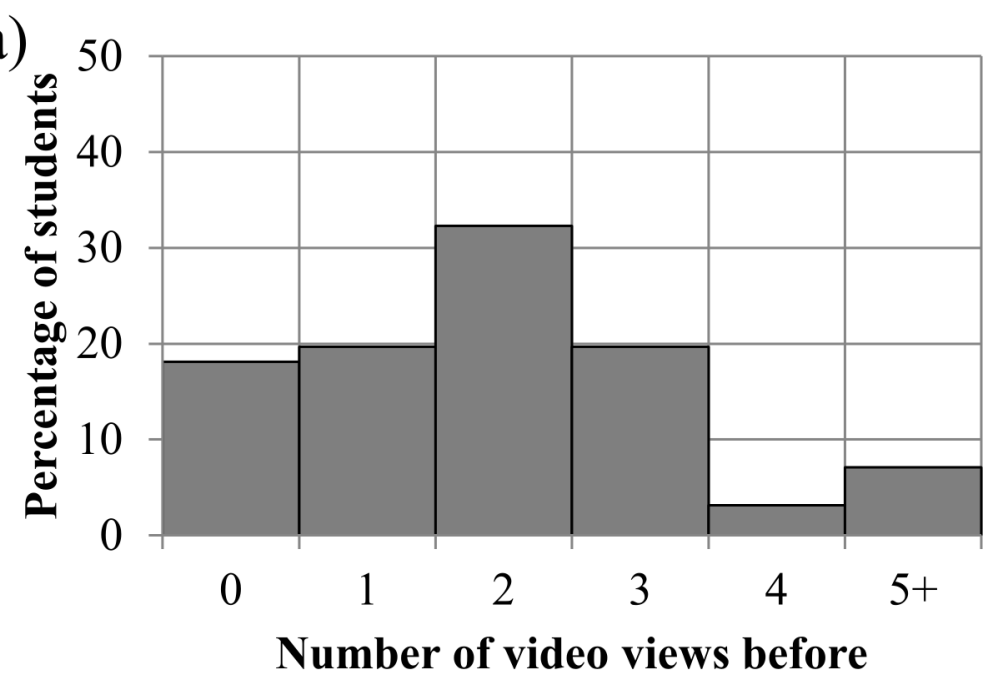

(b)

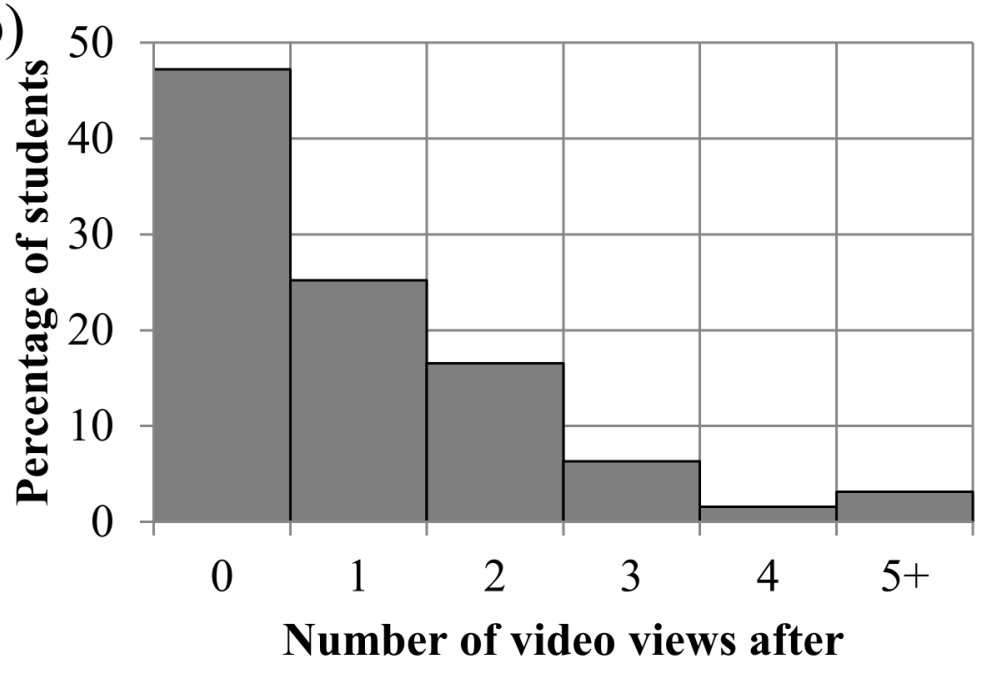




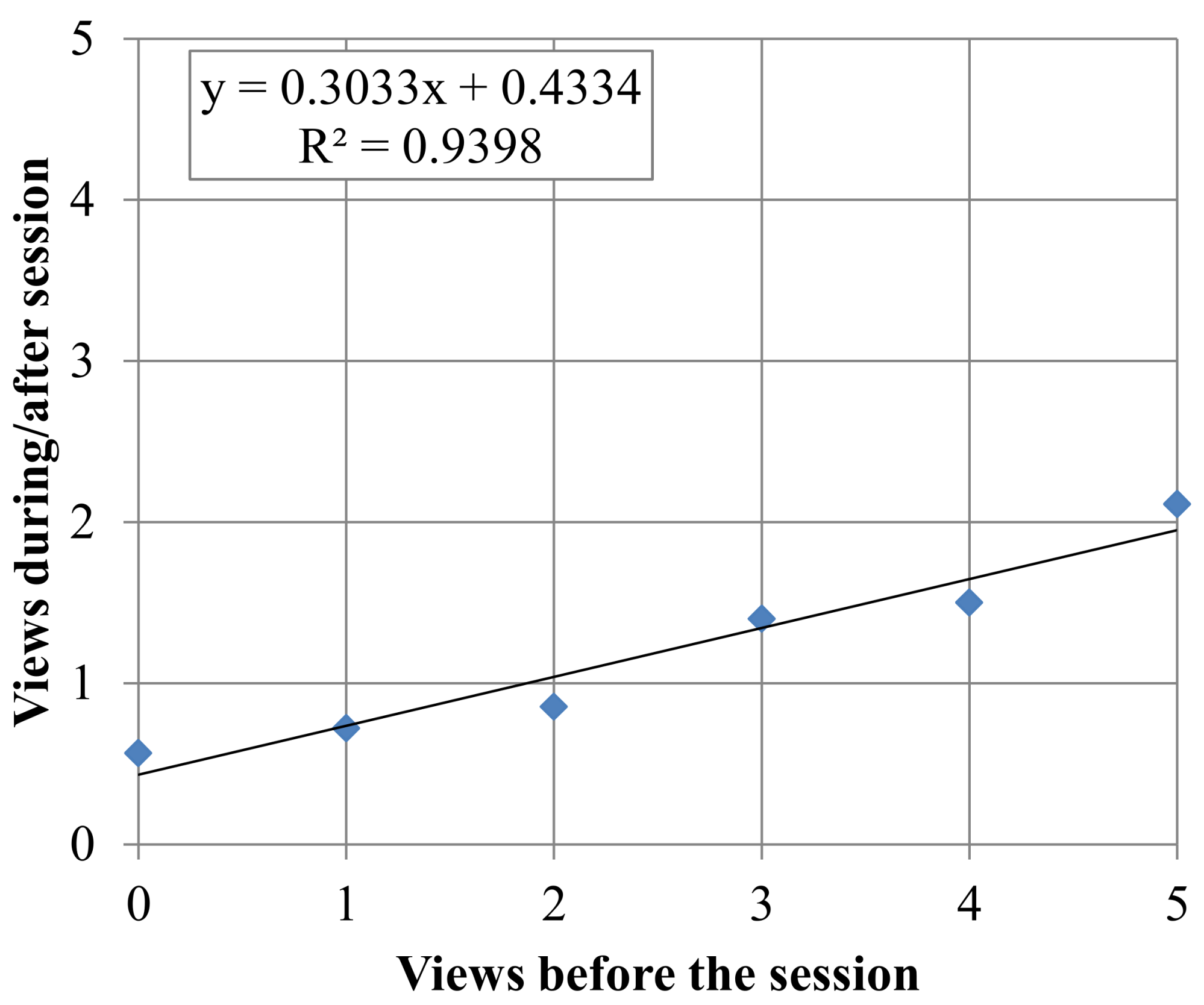


(a)

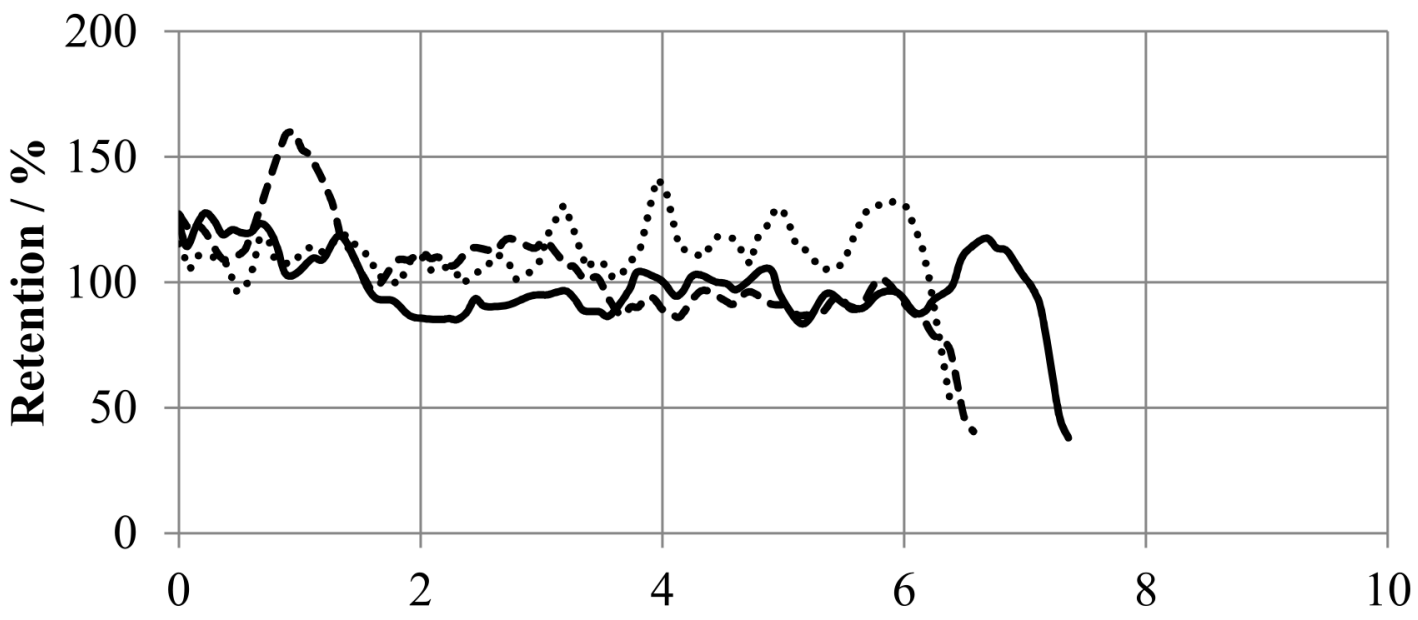

(b)

Time / min

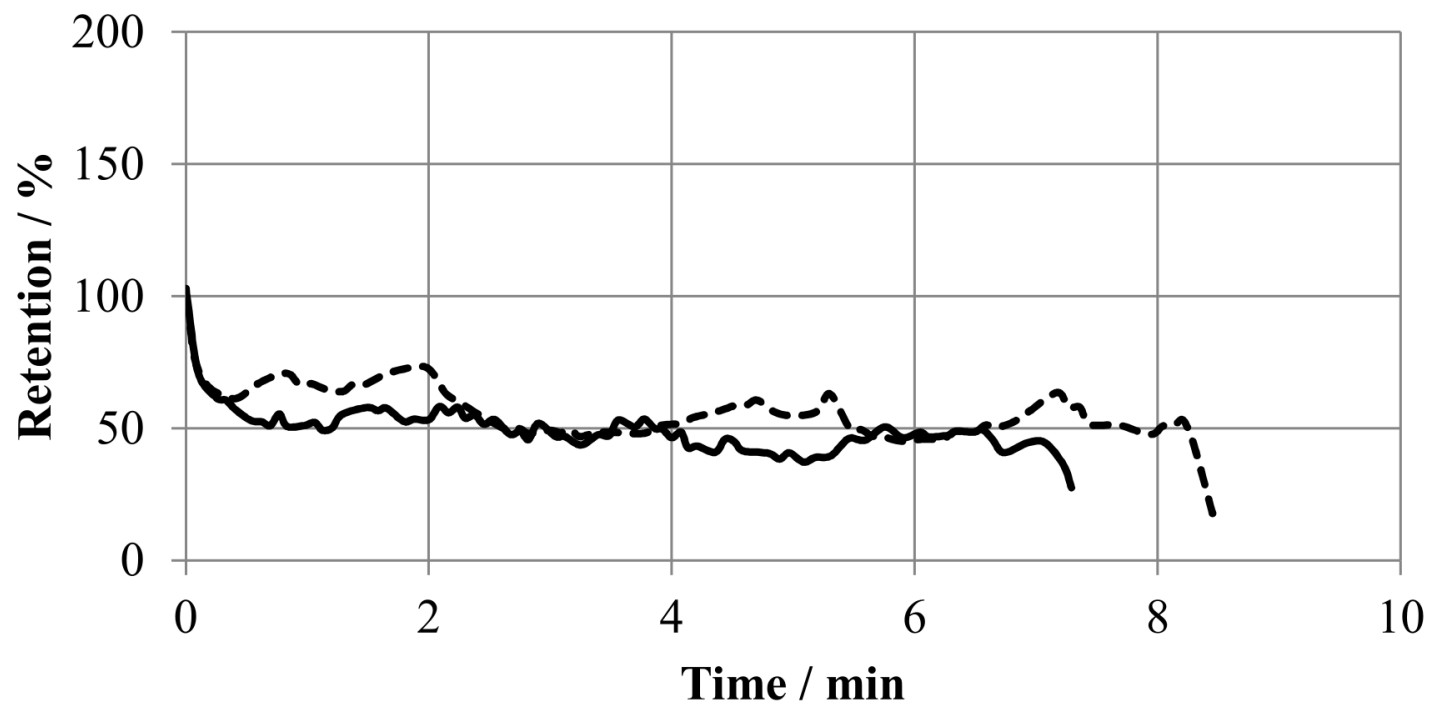


(a)

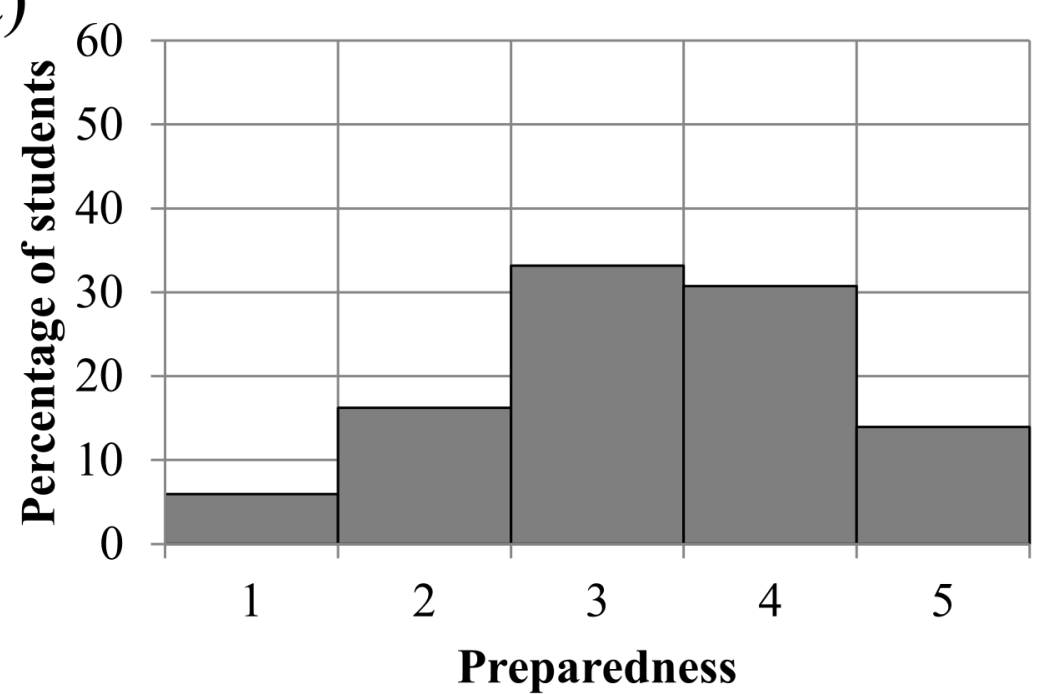

(c)

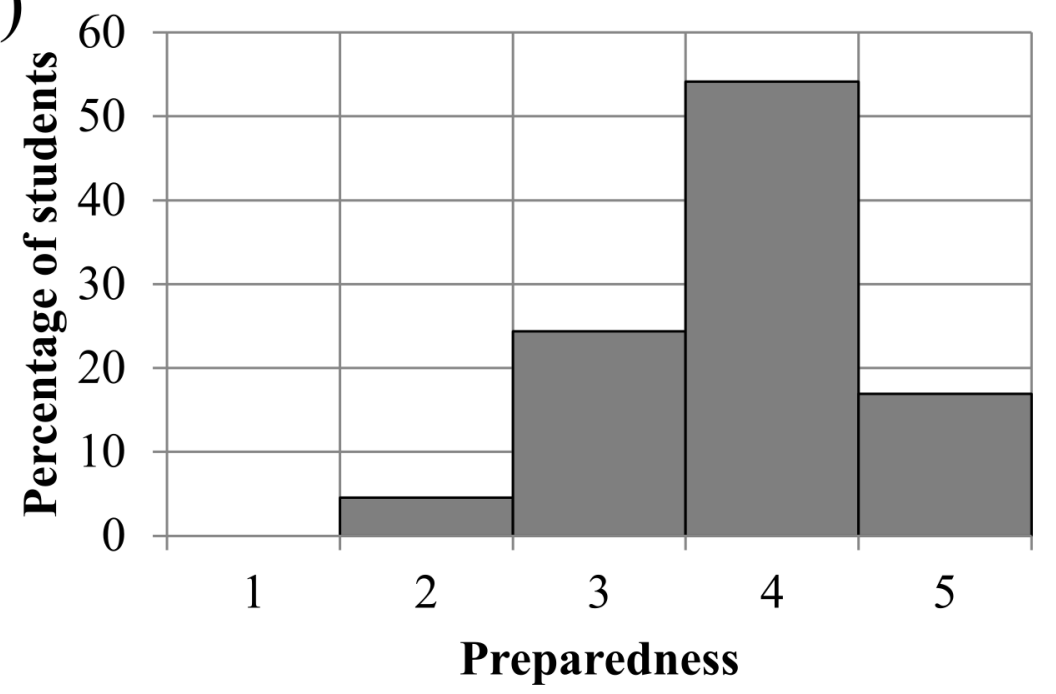

(b)

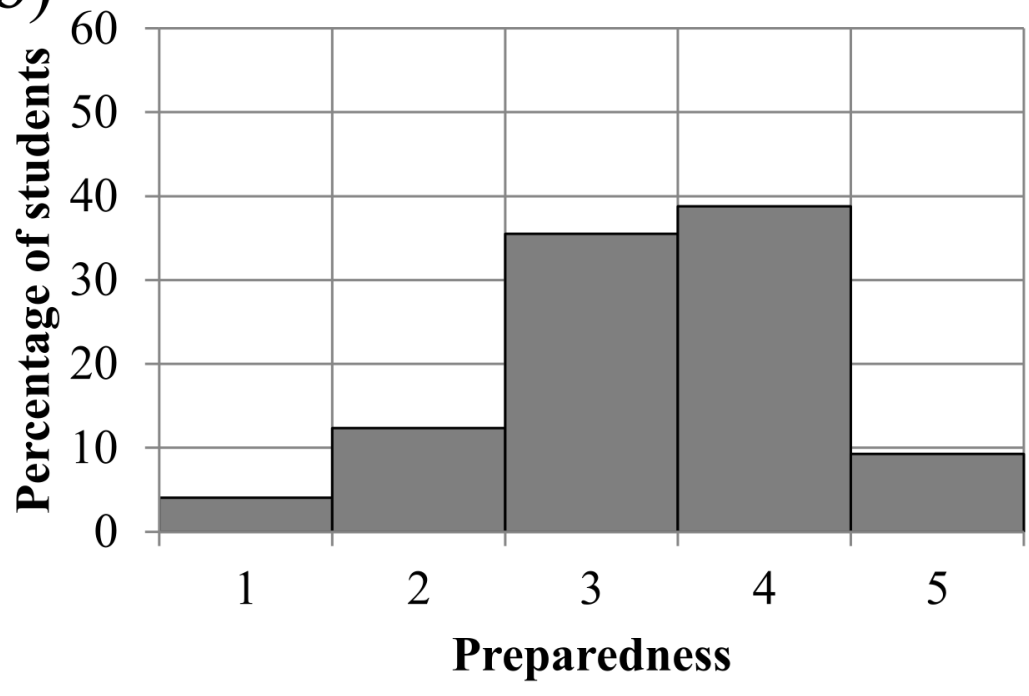

(d)

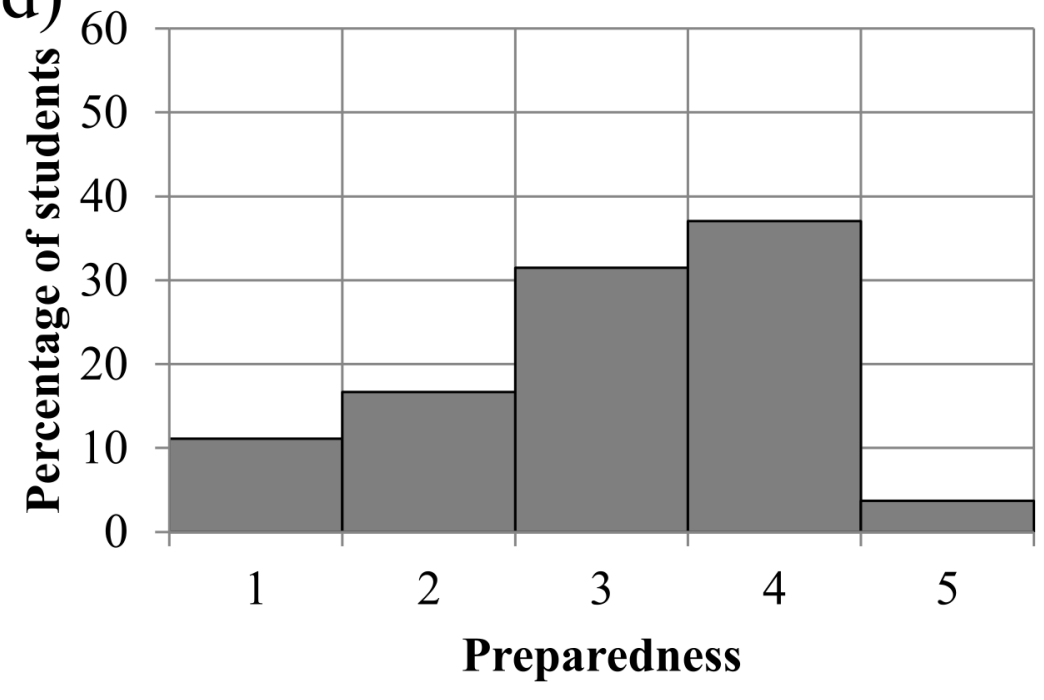




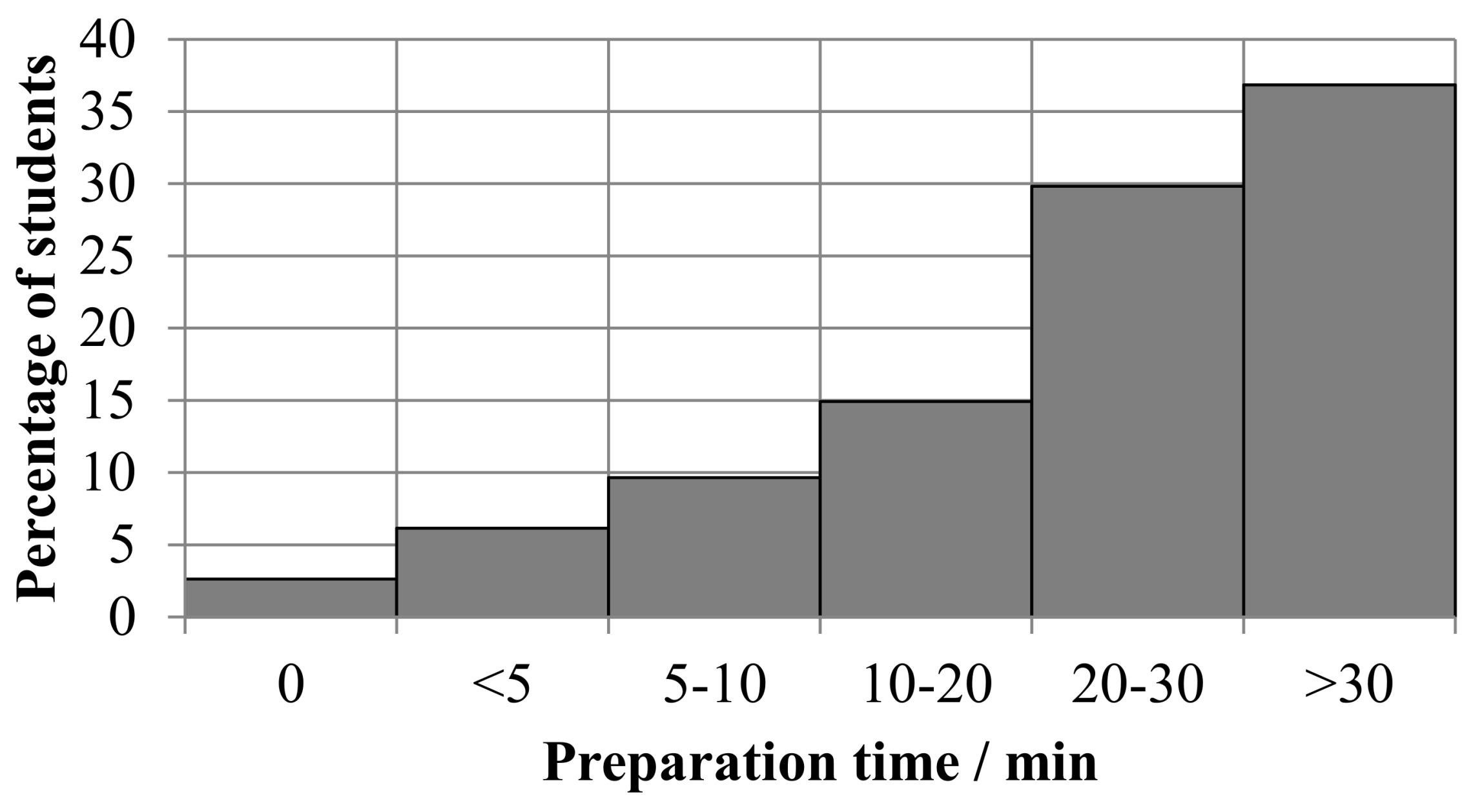




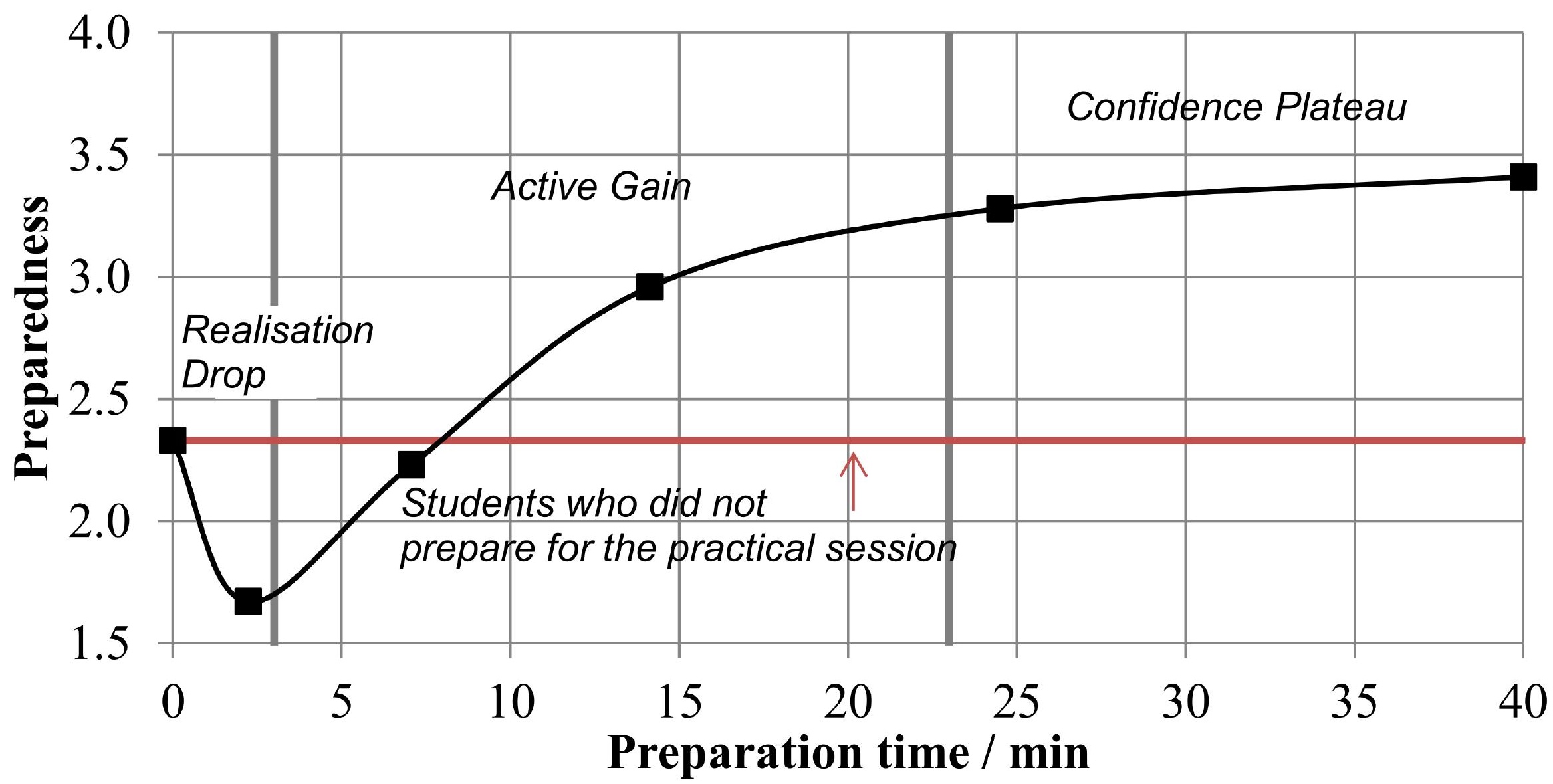

